\title{
AUTOCONCEITO ESCOLAR EM ALUNOS DO ENSINO FUNDAMENTAL
}

\author{
Leonardo Santos de Souza', Camélia Santina Murgo² \\ 'Universidade do Oeste Paulista - UNOESTE, Curso de Psicologia. Presidente Prudente, SP. E-mail: \\ leonardosouza.psicologia@gmail.com
}

\section{RESUMO}

Estudos destacam a importância da compreensão do autoconceito, definido como a percepção construída do indivíduo sobre si, a partir das interações sociais e ambientais. Dessa forma, a presente pesquisa teve como objetivo verificar os níveis de autoconceito, com ênfase no aspecto escolar, de 44 alunos, de ambos os sexos com idade entre 10 e 13 anos, matriculados nos 6으 e 7은 anos do ensino fundamental de uma escola pública no interior do estado de São Paulo. Quanto à metodologia, tratou-se de um estudo quantitativo, exploratório, de recorte transversal. Foi possível perceber que os alunos de ambos os sexos apresentaram escore autoconceito social, familiar e pessoal semelhantes. Porém, os garotos apresentaram autoconceito escolar superior às garotas, entretanto, ainda necessitam de fortalecimento. Conclui-se que ações interinstitucionais precisam ser realizadas visando o fortalecimento do autoconceito escolar dessas crianças em período de desenvolvimento.

Palavras chave: Autoconceito Escolar; Sala de Aula; Ensino Fundamental.

\section{SELF SCHOOL IN ELEMENTARY SCHOOL STUDENTS}

\begin{abstract}
A lot of studies highlight the importance of understanding the self, it is defined as the perception of the individual built on itself from the social and environmental interactions. Thus, this study aimed to verify the self-levels, with emphasis on the school aspect of 44 students, of both sexes between 10 and 13 years old, in 6th and 7th years of elementary education in a public school in the state of São Paulo. As for the methodology, this was a quantitative study, exploratory, crosscut. It was revealed that students of both sexes showed social self-concept scores, family and similar personnel. But the boys had higher self-concept school the girls, however, still need strengthening. It is concluded that interinstitutional actions need to be undertaken aimed at strengthening the school self-concept of these children developing period.

Keywords: Self School; Classroom; Elementary School.
\end{abstract}




\section{INTRODUÇÃO}

Pesquisas relacionadas ao autoconceito têm sido encontradas na literatura trazendo diversas perspectivas de compreensão sobre o construto. Para alguns estudiosos (Chapman, Tunmer e Prochnow, 2000; Formiga, 2004; Guay, Marsh e Boivin, 2003; Okano et al., 2004; Stevanato et al., 2003; Suehiro et al., 2009), o autoconceito é o principal preditor da qualidade das relações interpessoais, da criatividade, motivação, rendimento acadêmico e até mesmo do fracasso escolar. O que justifica a pertinência de se realizar investigações sobre o tema.

No que diz respeito a definição, existe uma concordância entre os autores, de que o autoconceito implica na avaliação que o indivíduo faz a seu respeito, sobre seu desempenho e suas interações com o outro, a partir de seu contexto sociocultural (GIOVANI e TAMAYO, 2003). Assim, o autoconceito determina a maneira pela qual o indivíduo se relaciona com o meio, com os outros e consigo mesmo.

No presente estudo o autoconceito será compreendido como a percepção que o individuo constrói sobre si durante seu ciclo vital no processo de interação social, a partir da influência dos ambientes em sendo inserido. (SISTO e MARTINELLI, 2004). Considerando então os autores citados, o autoconceito pode ser aprendido e resultará na avaliação que o individuo fará de suas capacidades, realizações e experiências em seus grupos sociais como a família, escola e outros contextos. Pode-se dizer então que o indivíduo construirá um autoconceito pessoal, familiar, social e escolar.

Particularmente, a investigação que aqui se propõe, terá como foco o autoconceito no contexto escolar o qual é entendido como o conjunto de representações que o aluno tem das suas competências para realização das tarefas escolares, bem como das avaliações que ele faz daquilo que realiza (SISTO e MARTINELLI, 2004). O autoconceito escolar tem sido apontado como um fator essencial para o rendimento acadêmico (BURNS, 1979; BYRNE, 1996). Isso porque, a experiência escolar do indivíduo tem desdobramentos na imagem que ele faz de si mesmo, levando em consideração que tais experiências podem ser cerceadoras ou estimuladoras das suas iniciativas à depender de como a escola compreende esse processo.

O estudo de Suehiro et al. (2009), que objetivou levantar as publicações nacionais dos últimos dez anos referentes à avaliação do autoconceito apontou que somente a partir do ano de 2005 é que o construto autoconceito começou a ser pesquisado no contexto escolar. E estas pesquisas referiam-se a crianças (50\%), 40\% foram compostas por adolescentes e adultos, enquanto apenas $10 \%$ (um artigo) investigaram crianças e adolescentes em sua amostra. Já os instrumentos de avaliação do autoconceito mais utilizados segundo o estudo, foram a Escala Infantil Piers-Harris e a Escala de Autoconceito Infanto-Juvenil EAC-IJ, o que revela um número pouco expressivo de instrumentos para essa finalidade.

A partir do cenário esboçado, com base nos resultados das pesquisas até então realizadas, o objetivo deste estudo foi examinar como os estudantes avaliam seu autoconceito, com ênfase no autoconceito escolar.

\section{METODOLOGIA}

A presente pesquisa foi inscrita e aprovada na Coordenadoria Central de Pesquisa da Universidade do Oeste Paulista (CCPq/UNOESTE), sob protocolo número 2519 em 2015. O estudo possui caráter quantitativo e modalidade exploratória. Quanto a temporalidade, optou-se por um recorte transversal.

A amostra foi composta por 44 estudantes, de ambos os sexos, de uma escola pública no interior do estado de São Paulo, com idade entre 11 e 13 anos, matriculados nos 6 e 70 anos do ensino fundamental. Para a coleta dos dados foi aplicada a Escala de Autoconceito InfantoJuvenil (EAC-IJ): elaborado por Sisto e Martinelli (2004), que visa avaliar diferentes níveis de autoconceito na criança e no adolescente, sendo eles o autoconceito pessoal, familiar, escolar e 
social, considerando o autoconceito como uma interação das pessoas com o ambiente durante todo o processo do seu desenvolvimento, acompanhado de uma avaliação acerca de experiências, capacidades, representações e realizações.

Para a coleta de dados, foi realizado contato com a instituição para autorização da realização do estudo. Em sequência os participantes foram convidados e receberam esclarecimentos quanto os objetivos da pesquisa e a necessidade de autorização dos pais ou responsáveis para participação. Nessa situação, foi solicitado aos alunos que encaminhassem aos pais ou responsáveis o Termo de Consentimento Livre e Esclarecido (TCLE). No momento da coleta, os alunos também assinaram o Termo de Assentimento Livre e Esclarecido (TALE), formalizando o aceite em colaborar com o estudo e respondendo o instrumento proposto. Os dados coletados foram analisados e categorizados com base no manual do instrumento utilizado (Escala de Autoconceito Infanto- Juvenil) - Sisto e Martinelli (2004).

\section{RESULTADOS}

Serão apresentados de forma descritiva, os resultados gerais das sub- escalas avaliadas de acordo com o manual da Escala de Autoconceito Infanto-Juvenil e posteriormente realizadas comparações do escore total de autoconceito escolar entre o gênero dos participantes. O manual apresenta as seguintes possibilidades de classificação: Abaixo de 25\%; 25\%; Abaixo de 50\%, 50\%; Abaixo de 75\%; 75\% e Acima de 75\%. Dessa forma, as tabelas abaixo apresentam médias dos resultados brutos obtidos entre os participantes e o quartil correspondente a cada sub escala de autoconceito.

Tabela 1. Média geral das subescalas de autoconceito infanto-juvenil.

\begin{tabular}{lcc} 
& Média & C. N.E \\
\hline EACIJ_Social & 9,61 & -75 \\
EACIJ_Pessoal & 4,97 & -75 \\
EACIJ_Familiar & 5,02 & -50 \\
EACIJ_Escolar & 4,06 & 50 \\
Geral & 23,68 & -50 \\
\hline
\end{tabular}

* C.N.E= Classificação na Escala.

A partir da correção do instrumento, baseado na análise classificatória do mesmo (Sisto e Martinelli, 2004), foi possível compreender que entre os participantes da amostra existe um desempenho médio referente ao autoconceito social, com média 9,61. Tal resultado indica que a classificação do autoconceito social foi de quartil abaixo de 75 , permitindo compreender que os alunos consideram-se inteligentes, sentem-se bem com seus amigos e buscam ajuda quando necessário. No que diz respeito ao autoconceito pessoal, foi encontrado como resultado entre os participantes classificação de quartil abaixo de 75 a partir do escore médio de 4,97. Esse resultado é positivo, pois indica que os participantes enxergam-se como pessoas tranquilas, sem medos e que sentem-se bem consigo. Em relação ao autoconceito familiar, encontrou-se um escore médio de 5,02 indicando uma classificação da sub- escala com quartil abaixo de 50 . Isto indica que os sujeitos encontram-se medianamente contentes com os irmãos, e realizam os afazeres relacionados à casa. Já no autoconceito escolar houve um escore médio entre os participantes de 4,06 indicando uma classificação de 50 no quartil. 0 presente resultado indica um desempenho médio. Isto significa que de uma forma geral, os alunos avaliados enxergam-se como espertos, tem suas colocações aceitas pelos colegas, apresentam um bom desempenho acadêmico e são considerados pelos colegas como bondosos e divertidos enquanto a outra metade enxergase de maneira contrária (SISTO, MARTINELLI, 2004). 
Não foi encontrada evidência estatística significativa de diferença nas pontuações entre os grupos feminino e masculino da amostra estudada. Porém, serão explanados abaixo os resultados obtidos comparando a pontuação bruta entre gênero.

Tabela 02. Média geral das subescalas de autoconceito infanto-juvenil por Gênero.

\begin{tabular}{lcc} 
FEMININO & Média & C.N.E \\
\cline { 2 - 2 } & 9,34 & -50 \\
EACIJ_Pessoal & 4,52 & 50 \\
EACIJ_Familiar & 5,39 & -50 \\
EACIJ_Escolar & 3,52 & 25 \\
EACIJ Geral & 22,78 & 25 \\
& & \\
MASCULINO & Média & C.N.E \\
EACIJ_Social & 9,90 & -75 \\
EACIJ_Pessoal & 5,47 & -75 \\
EACIJ_Familiar & 4,61 & -50 \\
EACIJ_Escolar & 4,67 & 50 \\
EACIJ Geral & 24,67 & 50 \\
\hline
\end{tabular}

* C.N.E= Classificação na Escala.

De maneira geral os escores médios de autoconceito social, pessoal e familiar entre os participantes de ambos os sexos apresentaram classificação similar na categorização de Sisto e Martinelli (2004). Porém, após a correção das subescalas foi possível perceber que entre os meninos, os resultados brutos e quartil de autoconceito, escolar e geral foi maior que das meninas. Estes resultados indicam que se comparados, os meninos veem a si mesmos como mais inteligentes que as meninas, apresentam vontade de ajudar os demais, pedem ajuda quanto necessitam e apresentam um bom relacionamento com os demais (autoconceito social). Ambos os sexos apresentaram escore semelhante, de 50 no autoconceito familiar, explicitando um resultado médio, indicando que a metade do grupo percebe-se como cuidadosas em relação às questões de casa, pais e irmãos, bem como autoconceito pessoal, onde os meninos apresentaram escore similar ao das meninas (classificação abaixo de 75) ao das meninas (classificação 50) na correção da escala. Este resultado indica que ambos os participantes, entre si, percebem-se como inteligentes, bem como ajudam os outros e sente-se bem consigo mesmos (SISTO, MARTINELLI, 2004).

Ainda na perspectiva dos autores, os meninos apresentaram autoconceito escolar (classificação 50) superior ao das meninas (quartil 25). Porém, mesmo os resultados dos meninos sendo superior ao das meninas, o escore ainda é relativamente baixo. Isto indica que parte significativa das meninas se percebem como não muito espertas para o estudo, não conseguem liderar alguma situação quando necessário, acreditam que suas ideias quase sempre serão rejeitadas (SISTO, MARTINELLI, 2004).

\section{DISCUSSÃO}

Foi possível identificar que o autoconceito escolar foi considerado insuficiente ou abaixo da média, para ambos os sexos baseando-se nas tabelas classificatórias do instrumento aplicado (EAC IJ). Partindo deste pressuposto podem ser mencionados achados empíricos que trazem a escola como um dos contextos sociais mais investigados no que diz respeito à promoção ao desenvolvimento do autoconceito (Veiga, 2001; Guay, Marsh e Boivin, 2003; Walker, 2004; Parker, 2009; Paiva e Lourenço, 2011; Fleith e Alencar, 2012). Esses estudiosos chamam a atenção para a importância de um clima de sala de aula caracterizado por uma atmosfera de aceitação e 
respeito entre colegas e professores; pelo incentivo a construção do conhecimento de forma reflexiva e crítica, pela promoção de autonomia e valorização dos interesses e habilidades dos alunos; favorecendo assim a aprendizagem e a avalição positiva dos alunos acerca de suas potencialidades.

Em complemento aos autores citados, Oliveira (2000) pontua que a escola pode ser cerceadora quando, por exemplo, valoriza conteúdos e currículos inapropriados, quando permite a discriminação dos alunos dentro da sala, fazendo com que desenvolvam sentimento de fracasso. Em contrapartida, julga-se a escola estimuladora, à medida que o professor aceita os limites de seus alunos, quando cria um clima agradável e de amizade na sala de aula.

\section{CONCLUSÃO}

A escola precisa adotar estratégias de trabalho interinstitucional e multidisciplinar visando garantir o bom desenvolvimento do autoconceito, especialmente o escolar, para que esses alunos em período de desenvolvimento possuam uma visão positiva de si e de suas habilidades e potencialidades, uma vez que isso pode influenciar os comportamentos futuros no que diz respeito sua relação com o processo de ensino-aprendizagem. Ações de promoção podem diminuir os números alarmantes de fracasso escolar, depressão infantil, além de promover bem estar subjetivo.

Sugerem-se novos estudos na área, com amostras mais representativas para que se amplie a discussão acerca da temática e generalizações sejam realizadas análises estatísticas significativas e de maior efetividade.

\section{REFERÊNCIAS}

BURNS, R. B. The self-concept. London: Longman, 1979.

BYRNE, B. M. Measuring self-concept across life span. Washington, DC: American Psychological Association. 1996.

CHAPMAN, James W.; TUNMER, William E.; PROCHNOW, Jane E. Early reading-related skills and performance, reading self-concept, and the development of academic self-concept: A longitudinal study. Journal of educational psychology, v. 92, n. 4, p. 703, 2000. https://doi.org/10.1037/0022$\underline{0663.92 .4 .703}$

FLEITH, D. S.; ALENCAR, E. M. L. S. Autoconceito e Clima Criativo em Sala de Aula na percepção de alunos do ensino fundamental.Psico-USF, Itatiba, v. 17, n. 2, p. 195-203, Aug. 2012

FORMIGA, N. S. O tipo de orientação cultural e sua influência sobre os indicadores do rendimento escolar. Psicol. teor. prat. São Paulo, v. 6, n. 1, jun. 2004.

GIOVANI, A.; TAMAYO, A. Inventário Masculino dos Esquemas de Gênero do Autoconceito (IMEGA). Psicologia: Teoria e Pesquisa, v 19 n. 3, p. 249-259, set-dez, 2003. https://doi.org/10.1590/S0102-37722003000300007

GUAY, F.; MARSH, H. W.; BOIVIN, M. Academic Self-Concept and Academic Achievement: Developmental Perspectives on Their Causal Ordering. Journal of Educational Psychology, v. $95 \mathrm{n}$. 1, p. 124-136, 2003. https://doi.org/10.1037/0022-0663.95.1.124 
OKANO, C. B. et al. Crianças com dificuldades escolares atendidas em programa de suporte psicopedagógico na escola: avaliação do autoconceito. Psicol. Reflex. Crit., Porto Alegre, v. 17, n. 1, p. 121-128, 2004.

OLIVEIRA, G. de C. et al. Autoconceito do adolescente. Leituras de psicologia para formação de professores. Petrópolis: Vozes, 2000.

PAIVA, M. O.; LOURENÇO, A. A. Ambiente da sala de aula: um estudo de caso. Educação e Filosofia Uberlândia, v. 25 n. 49, p. 17-42, 2011.

PARKER, A. K. Elementary organizational structures and young adolescents' self-concept and classroom environment perceptions across the transition to middle school. Journal of Research in Childhood Education, v. 23, n. 3, p. 325-339, 2009. https://doi.org/10.1080/02568540909594664

SISTO, F. F.; MARTINELLI, S. C. Escala de Autoconceito Infanto-Juvenil (EAC-IJ). Vetor Editora, Psicopedagógica: São Paulo, 2004.

STEVANATO, I. S. et al. Autoconceito de crianças com dificuldades de aprendizagem e problemas de comportamento. Psicol. estud., Maringá, v. 8, n. 1, p. 67-76, June 2003.

SUEHIRO, A. C. B. et al. Avaliação do Autoconceito no Contexto Escolar: Análise das Publicações em Periódicos Brasileiros. Psicologia Ciência e Profissão, v. 29 n. 1, p. 18-29, 2009. https://doi.org/10.1590/S1414-98932009000100003

VEIGA, F. H. Indisciplina e violência na escola: práticas comunicacionais para professores e pais. 2 ed. Coimbra: Almedina, 2001.

WALKER, S. L. Learning environment research: A review of the literature. 2004. Learning Environments Monograph n. 3, Texas State University, San Marcos. 